\title{
BMJ Open Impact of surgeon and anaesthesiologist sex on patient outcomes after cardiac surgery: a population-based study
}

\author{
Louise Y. Sun (1) , , ${ }^{1,3,4,5}$ Sylvain Boet, ${ }^{4,5,6}$ Vincent Chan, ${ }^{7}$ Douglas S. Lee, ${ }^{2,8}$ \\ Thierry G. Mesana, ${ }^{7}$ Anan Bader Eddeen, ${ }^{2}$ Cole Etherington (D) 4,5
}

To cite: Sun LY, Boet S, Chan V, et al. Impact of surgeon and anaesthesiologist sex on patient outcomes after cardiac surgery: a populationbased study. BMJ Open 2021;11:e051192. doi:10.1136/ bmjopen-2021-051192

- Prepublication history and additional supplemental material for this paper are available online. To view these files, please visit the journal online. (http://dx.doi.org/10.1136/ bmjopen-2021-051192).

Received 15 March 2021 Accepted 05 August 2021

Check for updates

(c) Author(s) (or their employer(s)) 2021. Re-use permitted under CC BY-NC. No commercial re-use. See rights and permissions. Published by BMJ.

For numbered affiliations see end of article.

Correspondence to

Dr Louise Y. Sun;

Isun@ottawaheart.ca

\section{ABSTRACT}

Background Effective teamwork between

anaesthesiologists and surgeons is essential for optimising patient safety in the cardiac operating room. While many factors may influence the relationship between these two physicians, the role of sex and gender have yet to be investigated.

Objectives We sought to determine the association between cardiac physician team sex discordance and patient outcomes.

Design We performed a population-based, retrospective cohort study.

Participants and setting Adult patients who underwent coronary artery bypass grafting (CABG) and/or aortic, mitral or tricuspid valve surgery between 2008 and 2018 in Ontario, Canada.

Primary and secondary outcome measures The primary outcome was all-cause 30-day mortality. Secondary outcomes included major adverse cardiovascular events at 30 days and hospital and intensive care unit lengths of stay (LOS). Mixed effects logistic regression was used for categorical outcomes and Poisson regression for continuous outcomes.

Results 79862 patients underwent cardiac surgery by 98 surgeons (11.2\% female) and 279 anaesthesiologists (23.3\% female); 19893 (24.9\%) were treated by sexdiscordant physician teams. Physician sex discordance was not associated with overall patient mortality or LOS; however, patients who underwent isolated CABG experienced longer hospital LOS when treated by an allmale physician team as compared with an all-female team (adjusted $\mathrm{OR}=1.07 ; \mathrm{p}=0.049$ ). When examining the impact of individual physician sex, the length of hospital stay was longer when isolated CABG procedures were attended by a male surgeon $(O R=1.10 ; p=0.004)$ or anaesthesiologist $(\mathrm{OR}=1.02 ; \mathrm{p}=0.01)$.

Conclusions Patient mortality and length of stay after cardiac surgery may vary by sex concordance of the attending surgeon-anaesthesiologist team. Further research is needed to examine the underlying mechanisms of these observed relationships.

\section{INTRODUCTION}

Teamwork between anaesthesiologists and surgeons, who share leadership roles in the operating room (OR), is critical for full team performance and patient outcome,

\section{Strengths and limitations of this study}

- Robust statistical methods were applied to a novel research question.

- Analyses were limited to physician characteristics.

- Information on gender was not available in the databases used; accordingly, only biological sex could be studied.

- Analyses were quantitative. Findings could be further explored in future qualitative studies.

particularly during times of crisis. ${ }^{1-3}$ Poor non-technical skills (eg, communication, teamwork, leadership) are one of the main contributing factors to adverse events in surgery. ${ }^{4}$ Incivility between the OR physician dyad has recently been demonstrated to impair anaesthesiologist performance and increase the likelihood of patient fatality during an operative crisis. ${ }^{3}$ In the cardiac OR (COR), where crisis situations are common, effective teamwork and communication between surgeons and anaesthesiologists may be even more important contributors to patient morbidity and mortality. ${ }^{5}$

While the quality of interactions between surgeons and anaesthesiologists may be driven by a variety of factors, emerging evidence suggests that sex (ie, biological attributes) and gender (ie, social constructed norms, roles, behaviours, expressions and identities) in particular warrant further investigation. In the broader realm of medical and surgical practice, physician sex and gender have been shown to influence physician practice patterns, ${ }^{6}$ medical education, ${ }^{7}$ assessment, ${ }^{8}$ remuneration, ${ }^{9}$ perceptions of safety culture, ${ }^{10}$ burnout, ${ }^{11}$ job satisfaction, ${ }^{11}$ psychological well-being ${ }^{11}$ and patient outcomes. $^{12} 13$ In the high stakes setting of the COR, physician sex and gender may be especially influential given the culmination of many stressors associated with implicit bias ${ }^{14}$ 
and a marked male predominance in comparison to other surgical specialties. ${ }^{15}$

Despite its potential importance to operative success and COR team-based culture, the association between surgeon and anaesthesiologist sex and patient outcomes has yet to be examined in this context. As a first step toward understanding the role of physician sex and gender in the COR, this study aimed to explore the association between physician sex discordance and patient outcomes after cardiac surgery. We hypothesised that better patient outcomes would be observed following cardiac surgery if cared for by COR teams comprised of a surgeon and anaesthesiologist of the same sex.

\section{METHODS}

Patient data were de-identified before access by the study authors. The data set from this study is held securely in coded form at ICES (formerly the Institutes for Clinical Evaluative Sciences). ${ }^{16}$ This study is reported in accordance to the Strengthening the Reporting of Observational Studies in Epidemiology checklist. ${ }^{17}$

\section{Design study population}

We conducted a population-based, retrospective cohort study of Ontario residents 18 years of age or older, who underwent first-time index coronary artery bypass grafting $(\mathrm{CABG})$, and/or aortic, mitral or tricuspid valve surgery between 1 October 2008 and 31 December 2018. Patient exclusion criteria were non-Ontario residency status, those with missing information regarding age and sex, and those who had concomitant arrhythmia, pulmonic valve or thoracic aorta surgery. In addition, patients treated by non-cardiac surgeons and those whose primary cardiac surgeon and/or anaesthesiologist could not be identified, were excluded. A flow diagram detailing the process used to select the study cohort is shown in online supplemental figure 1 .

\section{Data sources}

We used the clinical registry data from CorHealth Ontario and the population-level administrative healthcare databases from ICES. ICES is an independent, non-profit research institute whose legal status under Ontario's health information privacy law allows it to collect and analyse healthcare and demographic data, without consent, for health system evaluation and improvement. Ontario is Canada's most populous province with a publicly funded, universal healthcare system that reimburses all medically necessary services. CorHealth maintains a detailed prospective registry of all patients undergoing invasive cardiac procedures in Ontario from 20 advanced cardiac care hospitals. CorHealth demographic, comorbidity and procedural data has been validated through multiple chart audits. ${ }^{18}$

We deterministically linked the following administrative databases by using unique encoded identifier and analysed them at ICES. Date and type of cardiac procedure from the CorHealth registry was linked with the ICES Physicians Database (physician demographics and clinical specialty), Canadian Institute for Health Information's Discharge Abstract Database (CIHI-DAD; comorbidities and hospital admissions), Ontario Health Insurance Plan (OHIP) database (physician service claims), Registered Persons Database (vital statistics) and the Canadian census. These administrative databases have been validated for outcomes, exposures and comorbidities, including heart failure (HF), chronic obstructive pulmonary disease, asthma, hypertension, myocardial infarction (MI) and diabetes. ${ }^{19-21}$

\section{Patient and procedure characteristics}

Patient characteristics were identified from the CorHealth registry and supplemented with data from the CIHI-DAD and OHIP, using International Classification of Diseases (10th Revision; ICD-10-CA) codes within 5 years prior to the index procedure and according to validated algorithms. ${ }^{22}{ }^{23}$ We estimated each patient's socioeconomic status by using the neighbourhood median income from the Canadian census ${ }^{24}$ and determined residence status (rural vs urban) using Statistics Canada definitions. ${ }^{25}$ Height, weight and body mass index (BMI) were identified from the CorHealth Ontario registry and used to determine morbid obesity (defined as weight $>159 \mathrm{~kg}$ or BMI $\left.\geq 40 \mathrm{~kg} / \mathrm{m}^{2}\right) .{ }^{26}$ Frailty status was identified using the Johns Hopkins Adjusted Clinical Groups (ACG System) frailty-defining diagnoses indicator, which is an instrument designed and validated for research of frailty-related outcomes and resource utilisation using administrative data. ${ }^{27} 28$

Emergent procedural status was ascertained using the CorHealth registry and supplemented by OHIP code E020C for emergent procedures. ${ }^{26}{ }^{29}$ We defined procedure complexity as simple (isolated CABG or single valve) versus complex (multiple valves or combined valve(s)+CABG). Information on surgery duration was obtained from the CIHI-DAD.

\section{Exposures}

The primary exposure was surgeon-anaesthesiologist sex discordance (ie, surgeon and anaesthesiologist were of the opposite sex) versus concordance (ie, both treating physicians were of the same sex). Secondary exposures consisted of demographic characteristics of the primary surgeons and anaesthesiologists, including age, sex, years since medical school graduation, specialty, hospital and total number of procedures performed since the inception of ICES databases in 1991 until the date of the index procedure.

\section{Outcomes at $\mathbf{3 0}$ days}

Outcomes were assessed from the date of the procedure until 30 days postoperatively. The primary outcome was all-cause mortality. Secondary outcomes were hospital and intensive care unit (ICU) lengths of stay (LOS) as well as major adverse cardiovascular events (MACE). MACE was 
defined as a composite of stroke, repeat revascularisation, hospitalisation for MI and HF. Stroke included ischaemic stroke and was generally defined as new focal or global neurological deficit of cerebrovascular origin lasting 24 hours or longer that was not present before surgery.

\section{Statistical analysis}

LS and ABE had full access to all of the data in the study and take responsibility for its integrity and for the data analysis. Continuous variables were compared with a Student's t-test, or with a Wilcoxon rank-sum test for non-normally distributed data. Categorical variables were compared with a $\chi^{2}$ test. The association between physician sex discordance and patient outcomes was modelled using mixed effects logistic regression for categorical outcomes and Poisson regression for continuous outcomes. In each of these models, the choice of surgeon, anaesthesiologist and hospital were treated as random intercepts and physician, patient and procedure characteristics were fixed effects. We tested for potential effect modification by patient sex, procedure complexity, emergent operative status and hospital type (teaching vs community) using multiplicative interaction terms.

\section{Subgroup analysis}

Subgroup analyses were planned a priori. Surgeons who underwent subspecialised training (eg, valvular repair) are more likely to excel in these procedures. However, CABG is a 'bread and butter' cardiac procedure in which reduced variations in surgical results are expected to occur. We therefore also performed our analyses in patients who underwent isolated CABG.

\section{Sensitivity analyses}

We repeated our multivariable analyses first by further classifying physician sex into male surgeon-male anaesthesiologist, male surgeon-female anaesthesiologist, female surgeon-male anaesthesiologist and female surgeon-female anaesthesiologist. Next, we studied individually the impact of surgeon and anaesthesiologist sex.

Analyses were performed using SAS V.9.4 (SAS Institute) and R V.3.5.3 (R Foundation, Austria). Statistical significance was defined as a two-sided $p$ value of $<0.05$.

\section{Patient and public involvement}

Patients and the public were not involved in the conduct of this research study.

\section{RESULTS}

A total of 79862 patients who underwent first-time cardiac surgery met our inclusion criteria (23.4\% female). During the study period, surgeries were performed by 98 surgeons (11.2\% female) and 279 anaesthesiologists $(23.3 \%$ female), who formed 2079 unique physician teams $(3.0 \%$ both female, $67.6 \%$ both male, $9.0 \%$ female surgeon-male anaesthesiologist, 20.4\% male surgeon-female anaesthesiologist). A total of 19893 (24.9\%) patients were treated by sex-discordant COR physician teams $(7.2 \%$ by female surgeon-male anaesthesiologist, $17.7 \%$ male surgeon-female anaesthesiologist). In contrast, $1188(1.5 \%)$ patients were treated by all-female physician teams and $58.781(73.6 \%)$ by allmale teams.

While most baseline patient characteristics were similar between those treated by sex discordant versus concordant physicians (table 1), those treated by sex discordant physicians were more likely to be morbidly obese, to undergo surgeries of longer duration, but were less likely to be frail. No clinically significant differences were observed in the characteristics of physicians who treated female versus male patients (table 2).

\section{Mortality}

A total of $335(1.7 \%)$ patients treated by sex discordant and $1052(1.8 \%)$ by sex concordant physicians died within 30 days of surgery $(\mathrm{p}=0.51$, table 3 ). The adjusted OR of 30-day mortality was 0.93 (95\% CI 0.80 to 1.07 ) for sex discordant physicians, and none of the other physician characteristics were independent mortality risk factors (table 4). The association of physician sex discordance and 30-day mortality was not modified by patient sex (interaction $\mathrm{p}=0.33$ ), complex surgery (interaction $\mathrm{p}=0.20$ ), emergent operative status (interaction $\mathrm{p}=0.92$ ) and hospital type (interaction $\mathrm{p}=0.92$ ).

A total of $205(1.3 \%)$ patients who underwent isolated patients with CABG by sex discordant and 654 (1.4\%) by sex concordant physicians died within 30 days of surgery $(\mathrm{p}=0.41$, online supplemental table 1$)$. Physician sex discordance was not associated with 30-day mortality (adjusted OR 0.88 (95\% CI 0.74 to 1.05), online supplemental table 2), and we did not observe a statistically significant interaction between physician sex discordance and patient sex (interaction $\mathrm{p}=0.59$ ), off-pump CABG (interaction $\mathrm{p}=0.06$ ), emergent operative status (interaction $\mathrm{p}=0.57$ ) and hospital type (interaction $\mathrm{p}=0.62)$.

\section{MACE}

At 30 days, MACE occurred in 678 (3.4\%) patients who were treated by sex discordant and $2247(3.7 \%)$ by sex concordant physicians $(\mathrm{p}=0.03$, table 3$)$. Neither physician sex discordance (adjusted OR 0.96 (95\% CI 0.87 to $1.06)$ ), nor any other physician characteristics, were independently associated with MACE (online supplemental table 3). No modifiers of the association of physician sex discordance with MACE were identified.

In patients who underwent isolated CABG, 524 (3.3\%) treated by sex discordant and $1692(3.6 \%)$ by sex concordant physicians developed MACE ( $\mathrm{p}=0.12$, online supplemental table 1 ). We did not observe a statistically significant association between physician sex discordance and MACE (adjusted OR 0.99 (95\% CI 0.98 to 1.11), online supplemental table 2), and no effect modifiers of the association between physician sex discordance and MACE were identified. 
Table 1 Patient characteristics by surgeon-anaesthesiologist sex discordance in all cardiac surgery patients

\begin{tabular}{|c|c|c|c|c|}
\hline Variable & $\begin{array}{l}\text { Discordant } \\
(n=19893)\end{array}$ & $\begin{array}{l}\text { Concordant } \\
(\mathrm{n}=59969)\end{array}$ & $\begin{array}{l}\text { Standardised } \\
\text { difference }\end{array}$ & $P$ value \\
\hline Age, mean $\pm S D$, years & $66.3 \pm 10.4$ & $66.4 \pm 10.4$ & 0 & 0.76 \\
\hline Female sex, n (\%) & $4678(23.5)$ & $14010(23.4)$ & 0 & 0.66 \\
\hline \multicolumn{5}{|l|}{ Income quintile, $\mathrm{n}(\%)$} \\
\hline 1 & $3762(18.9)$ & $11771(19.6)$ & 0.02 & 0.01 \\
\hline 2 & 3966 (19.9) & $12374(20.6)$ & 0.02 & \\
\hline 3 & $4162(20.9)$ & $12226(20.4)$ & 0.01 & \\
\hline 4 & $4052(20.4)$ & $11970(20.0)$ & 0.01 & \\
\hline 5 & 3951 (19.9) & $11628(19.4)$ & 0.01 & \\
\hline Rural residence, $\mathrm{n}(\%)$ & $17212(86.5)$ & $50595(84.4)$ & 0.06 & $<0.001$ \\
\hline \multicolumn{5}{|l|}{ Hospital type, n (\%) } \\
\hline Community & $6236(31.3)$ & $18104(30.2)$ & 0.03 & 0.002 \\
\hline Teaching & $13657(68.7)$ & $41865(69.8)$ & 0.03 & \\
\hline Hypertension, n (\%) & $17203(86.5)$ & $51845(86.5)$ & 0 & 0.93 \\
\hline Atrial fibrillation, $\mathrm{n}(\%)$ & $1256(6.3)$ & $3830(6.4)$ & 0 & 0.72 \\
\hline Recent MI within 30 days, $n$ (\%) & $5002(25.1)$ & $15047(25.1)$ & 0 & 0.88 \\
\hline Remote MI, n (\%) & $4129(20.8)$ & $13003(21.7)$ & 0.02 & 0.006 \\
\hline Previous PCI, n (\%) & $3048(15.3)$ & $9161(15.3)$ & 0 & 0.88 \\
\hline \multicolumn{5}{|l|}{ Left ventricular ejection fraction, $\mathrm{n}(\%)$} \\
\hline$\geq 50$ & $13768(69.2)$ & $41267(68.8)$ & 0.01 & 0.37 \\
\hline $35-49$ & $4257(21.4)$ & $12841(21.4)$ & 0 & \\
\hline $20-35$ & $1591(8.0)$ & $4949(8.3)$ & 0.01 & \\
\hline$<20$ & $277(1.4)$ & $912(1.5)$ & 0.01 & \\
\hline Heart failure, $n(\%)$ & $4703(23.6)$ & $14697(24.5)$ & 0.02 & 0.01 \\
\hline Peripheral arterial disease, n (\%) & $2334(11.7)$ & $7040(11.7)$ & 0 & 0.98 \\
\hline Cerebrovascular disease $\mathrm{n}(\%)$ & $1952(9.8)$ & $5887(9.8)$ & 0 & 0.99 \\
\hline Dementia, n (\%) & $31(0.2)$ & $132(0.2)$ & 0.01 & 0.08 \\
\hline Depression, n (\%) & $300(1.5)$ & $814(1.4)$ & 0.01 & 0.12 \\
\hline Psychosis, n (\%) & $31(0.2)$ & $132(0.2)$ & 0.01 & 0.08 \\
\hline \multicolumn{5}{|l|}{ Smoking status, $\mathrm{n}(\%)$} \\
\hline Never & $8759(44.0)$ & $26942(44.9)$ & 0.02 & 0.001 \\
\hline Current & $3852(19.4)$ & $11922(19.9)$ & 0.01 & \\
\hline Former & $7282(36.6)$ & 21105 (35.2) & 0.03 & \\
\hline $\begin{array}{l}\text { Chronic obstructive pulmonary disease, } n \\
\text { (\%) }\end{array}$ & $5705(28.7)$ & $17303(28.9)$ & 0 & 0.64 \\
\hline Pulmonary circulation disorder, n (\%) & $387(1.9)$ & $1195(2.0)$ & 0 & 0.68 \\
\hline \multicolumn{5}{|l|}{ Serum creatinine ( $\mu \mathrm{mol} / \mathrm{L}), \mathrm{n}(\%)$} \\
\hline$<120$ & $17529(88.1)$ & $52151(87.0)$ & 0.03 & $<0.001$ \\
\hline $120-179$ & $1736(8.7)$ & $5670(9.5)$ & 0.03 & \\
\hline$\geq 180$ & $628(3.2)$ & $2148(3.6)$ & 0.02 & \\
\hline Dialysis, $\mathrm{n}(\%)$ & $384(1.9)$ & $1298(2.2)$ & 0.02 & 0.05 \\
\hline Diabetes, n (\%) & $8994(45.2)$ & $27182(45.3)$ & 0 & 0.78 \\
\hline Hypothyroidism, n (\%) & $406(2.0)$ & $1004(1.7)$ & 0.03 & $<0.001$ \\
\hline Morbid obesity, n (\%) & $9471(47.6)$ & $25824(43.1)$ & 0.09 & $<0.001$ \\
\hline Primary cancer, n (\%) & $980(4.9)$ & $2928(4.9)$ & 0 & 0.80 \\
\hline
\end{tabular}


Table 1 Continued

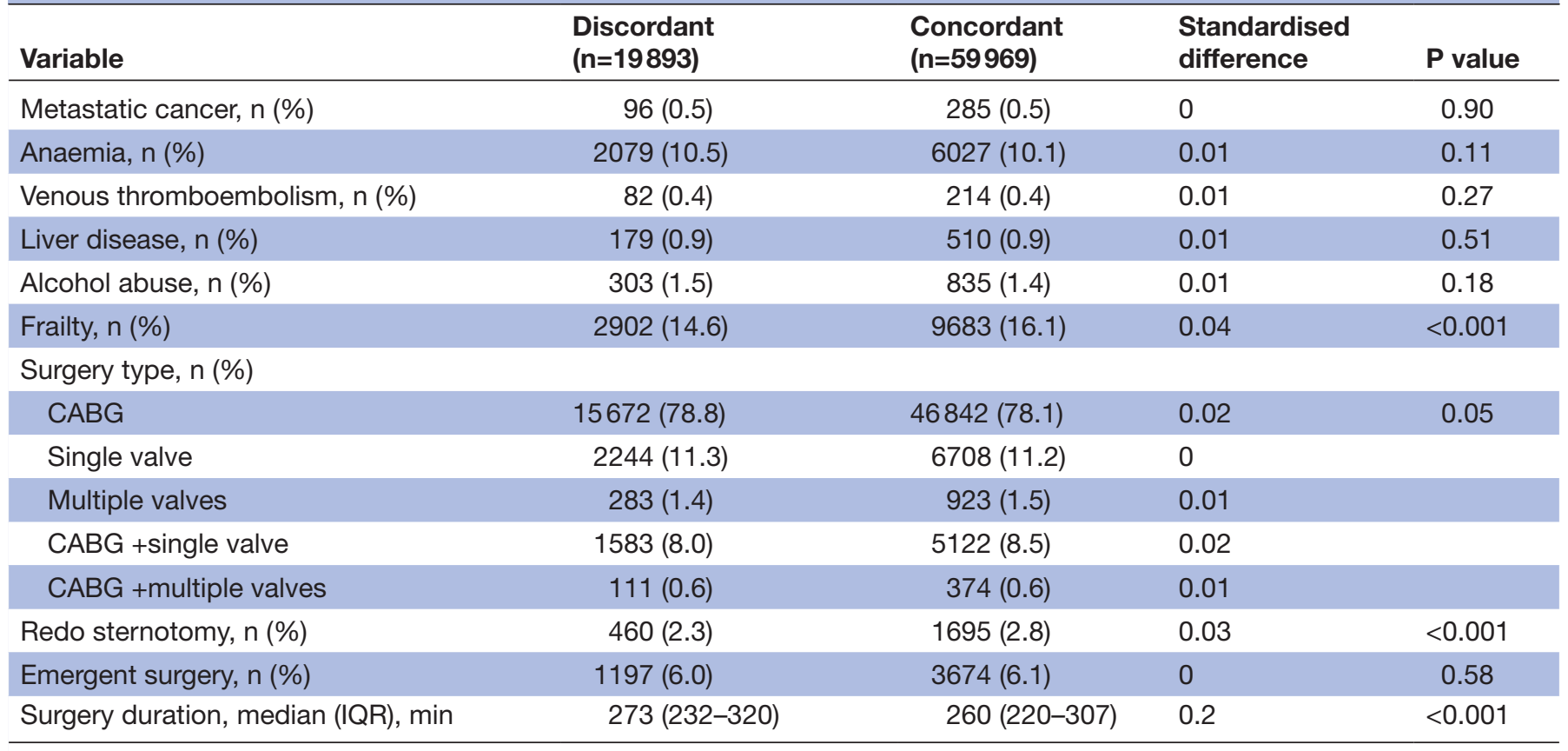

CABG, coronary artery bypass grafting; $\mathrm{MI}$, myocardial infarction; $\mathrm{PCl}$, percutaneous coronary intervention.

\section{ICU and hospital LOS}

Median ICU and hospital LOS were 2 days (IQR, 2-3) and 7 days (6-9), respectively, both in patients who were treated by sex discordant and concordant physicians (table 3). Physician sex discordance was not associated with ICU or hospital LOS in the overall (online supplemental table 4) nor the isolated CABG group (online supplemental table 2), and no effect modifiers were identified of the association between physician sex discordance and ICU/hospital LOS.

\section{Sensitivity analyses}

Surgeon-anaesthesiologist sex as a four-level categorical variable We did not observe an independent association between teams comprised of male surgeon-male anaesthesiologist, male surgeon-female anaesthesiologist, female

Table 2 Physician characteristics by patient sex

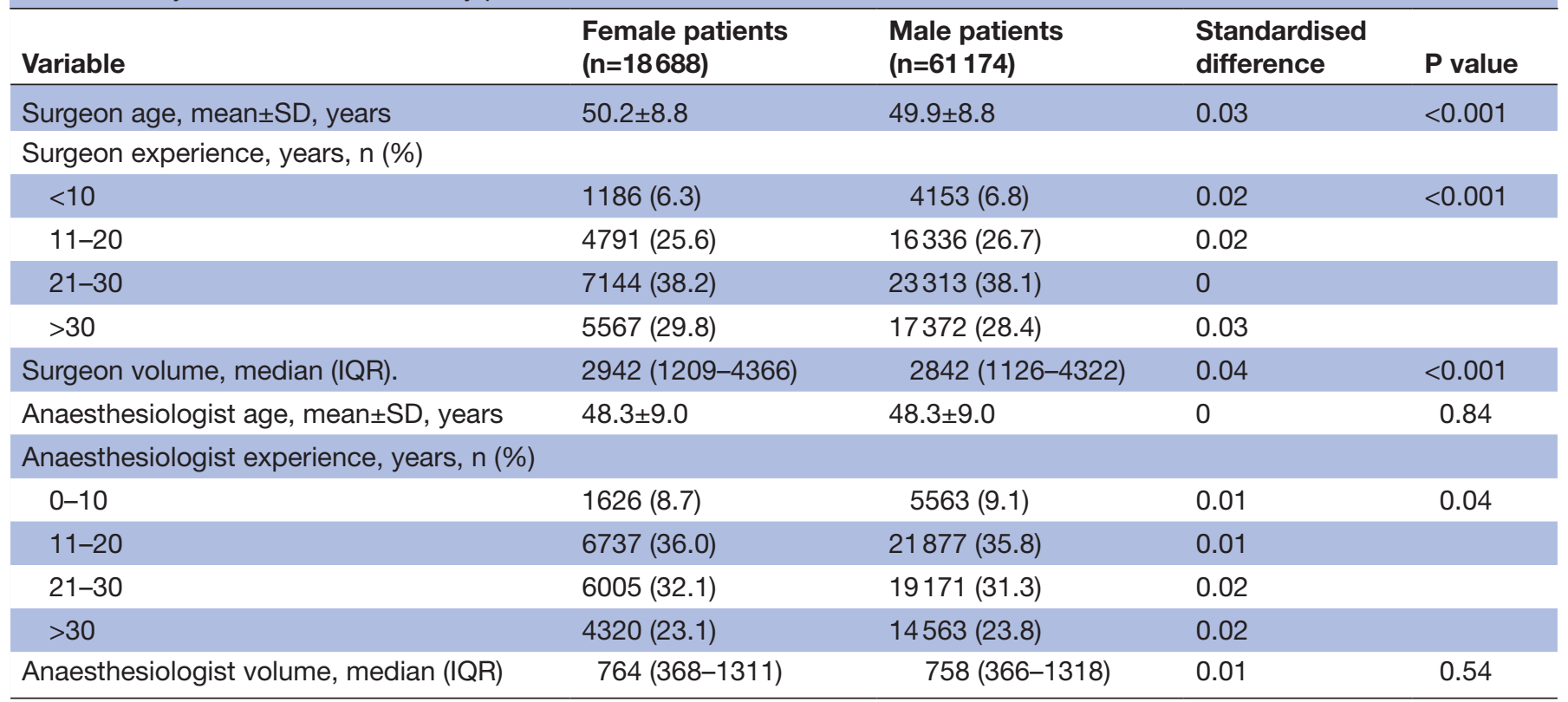

Total case volumes reflect the number of cases performed since 1991 until the date of the index procedure. 
Table 3 Thirty-day patient outcomes by physician sex discordance

\begin{tabular}{lcccc} 
Variable & $\begin{array}{l}\text { Discordant } \\
(\mathbf{n = 1 9 8 9 3 )}\end{array}$ & $\begin{array}{l}\text { Concordant } \\
(\mathbf{n = 5 9 9 6 9 )}\end{array}$ & Standardised difference & P value \\
\hline Mortality, $\mathrm{n}(\%)$ & $335(1.7)$ & $1052(1.8)$ & 0.01 & 0.51 \\
MACE, n (\%) & $678(3.4)$ & $2247(3.7)$ & 0.02 & 0.03 \\
Hospital length of stay, median (IQR), days & $7(6-9)$ & $7(6-9)$ & 0.03 & $<0.001$ \\
ICU length of stay, median (IQR), days & $2(2-4)$ & $2(2-4)$ & 0.06 & $<0.001$ \\
\hline
\end{tabular}

ICU, intensive care unit; MACE, major adverse cardiovascular events.

surgeon-male anaesthesiologist and female surgeon-female anaesthesiologist and 30-day mortality, MACE or ICU LOS (online supplemental table 5A,B). However, an all-male physician team as compared with an all-female team was associated with longer hospital LOS in patients with $\mathrm{CABG}$ (adjusted OR=1.07 (95\% CI 1.00 to 1.15 ); $\mathrm{p}=0.049$ ) (online supplemental table 6A).

\section{Individual contribution of surgeon and anaesthesiologist sex}

Male as compared with female surgeon (adjusted $\mathrm{OR}=1.10$ (95\% CI 1.03 to 1.18); $\mathrm{p}=0.004$ ), and male versus female anaesthesiologist (adjusted OR=1.02 (95\% CI 1.00 to $1.04) ; p=0.01$ ), was associated with longer hospital LOS in the overall and patient with CABG groups (online supplemental table $6 \mathrm{~B}$ ).

\section{Post-hoc analyses}

We conducted a post-hoc power analysis to determine whether the lack of observed between group mortality difference was due to the small number of outcome events. Using logistic regression with a sample size of 79862 patients $(24.9 \%$ treated by sex discordant surgeon-anaesthesiologist pairs) and an observed OR of 0.93 , we were able to achieve $19 \%$ power at a 0.05 significance level. At the request of the reviewers, we repeated our analysis for the composite end point of death and MACE. The findings of this post-hoc analysis also did not reach statistical significance (adjusted OR, 0.96 (95\% CI 0.88 to 1.05), $\mathrm{p}=0.37$; online supplemental table 7 ).

\section{DISCUSSION}

\section{Key findings}

The novelty of the present study lies in its consideration of the impact of surgeon-anaesthesiologist dyad on patient outcomes after cardiac surgery. Our key findings are as follows: (1) Physician sex discordance was not associated with overall patient mortality or LOS; (2) Patients who underwent isolated CABG experienced longer hospital LOS when treated by an all-male physician team as compared with an all-female team; (3) When examining the impact of individual physician sex, the length of hospital stay was clinically and statistically significantly longer when procedures were attended by a male surgeon.

\section{Interpretation}

We found that physician sex discordance was not associated with overall patient mortality or LOS. This stands contrary to our hypothesis as well as reports from other studies suggesting a greater opportunity for tension within sex discordant teams. For example, studies based on noncardiac OR teams suggest female providers may more often be challenged and perceived negatively by others, and are less likely to speak up when an incorrect decision is made. ${ }^{63031}$ Teamwork behaviours such as cooperation, communication and leadership, have also been observed to vary depending on the number of male and female providers in the room. ${ }^{631} 32$ Our findings suggest that sex diversity in the COR may actually increase cooperation. ${ }^{32}$ In fact, the COR teamwork culture may be changing in recent years, such that sex discordant surgeon-anaesthesiologist pairs are working more effectively together in achieving the observed lower rates of mortality. Further research is needed to qualitatively determine the relevance of this finding to teamwork quality and physician performance.

While previous studies have investigated the role of physician sex individually for surgeons, ${ }^{12}$ and primary care practitioners, ${ }^{33}$ we extended this analysis to include the dynamic relationship of the cardiac surgeon and anaesthesiologist team. A recent study of 25 cardiac and non-cardiac procedure types performed in Ontario, found that patients treated by female surgeons compared with male surgeons had a lower 30-day mortality (adjusted OR 0.88 (95\% CI 0.79 to 0.99$) ; \mathrm{p}=0.04){ }^{12}$ These authors postulated, however, that better outcomes in the hands of female surgeons may have been confounded by a higher volume of non-emergent, non-complex procedures being performed by this group. Our subgroup analysis in patients who underwent CABG, a routine procedure, was aimed to overcome this case allocation bias. We observed clinically and statistically significant longer lengths of hospital stay in those treated by all-male surgeon-anaesthesiologist teams as compared with all-female teams, as well as individually by male surgeons. Though researchers have postulated a variety of reasons for better patient outcomes among female surgeons ${ }^{12} 13$ and primary care physicians, ${ }^{33}$ less work has been done to examine how sex and gender may influence anaesthesia practice or team-based work in the COR. Our findings may in part 
Table 4 Predictors of all-cause patient mortality at 30 days, by surgeon-anaesthesiologist sex discordance

\begin{tabular}{lll}
\hline Variable & Adjusted OR $(95 \%$ Cl) & P value \\
\hline $\begin{array}{ll}\text { Physician characteristics } \\
\text { Physician sex }\end{array}$ discordance & $0.93(0.80$ to 1.07$)$ & 0.30 \\
\hline
\end{tabular}

\begin{tabular}{|c|c|c|}
\hline \multicolumn{3}{|c|}{ Surgeon experience, years } \\
\hline$<10$ & Reference & Reference \\
\hline $11-20$ & 1.24 (0.93 to 1.66$)$ & 0.14 \\
\hline $21-30$ & 1.07 (0.76 to 1.51$)$ & 0.71 \\
\hline$>30$ & 1.26 (0.83 to 1.91$)$ & 0.28 \\
\hline $\begin{array}{l}\text { Surgeon volume, per } \\
100 \text { cases }\end{array}$ & 1.00 (0.99 to 1.01$)$ & 0.55 \\
\hline $\begin{array}{l}\text { Anaesthesiologist } \\
\text { volume, per } 100 \text { cases }\end{array}$ & 1.00 (0.99 to 1.02$)$ & 0.79 \\
\hline
\end{tabular}

Anaesthesiologist experience, years

\begin{tabular}{|llc}
\hline$<10$ & Reference & Reference \\
\hline $11-20$ & $1.15(0.92$ to 1.45$)$ & 0.22 \\
$21-30$ & $1.01(0.78$ to 1.31$)$ & 0.93 \\
$>30$ & $1.03(0.78$ to 1.37$)$ & 0.82 \\
\hline $\begin{array}{l}\text { Patient characteristics } \\
\text { Patient age, per }\end{array}$ & $1.69(1.57$ to 1.80$)$ & $<0.001$ \\
10year & & \\
\hline
\end{tabular}

Female patient sex $\quad 1.56(1.37$ to 1.77$) \quad<0.001$

Income quintile

\begin{tabular}{|llllllc|}
\hline 1 & $1.44(1.20$ to 1.73$)$ & $<0.001$ & & thromboembolism & & \\
\hline 2 & $1.24(1.03$ to 1.48$)$ & 0.03 & & Liver disease & $1.45(0.94$ to 2.25$)$ & 0.09 \\
\hline 3 & $1.19(0.99$ to 1.44$)$ & 0.07 & Alcohol abuse & $1.21(0.80$ to 1.81$)$ & 0.37 \\
\hline 4 & $1.09(0.90$ to 1.33$)$ & 0.36 & Frailty & $0.82(0.71$ to 0.95$)$ & 0.01 \\
\hline 5 & Reference & Reference & Redo sternotomy & $1.10(0.87$ to 1.40$)$ & 0.44 \\
\hline Rural residence & $0.95(0.81$ to 1.12$)$ & 0.57 & Emergent surgery & $2.91(2.49$ to 3.39$)$ & $<0.001$ \\
\hline Community hospital & $1.24(0.81$ to 1.91$)$ & 0.33 & Complex surgery & $1.32(1.14$ to 1.53$)$ & 0.0002 \\
\hline Hypertension & $1.01(0.81$ to 1.25$)$ & 0.95 & Surgery duration, per & $1.07(1.07$ to 1.08$)$ & $<0.001$ \\
\hline Atrial fibrillation & $1.14(0.97$ to 1.35$)$ & 0.11 & 10min & & \\
\hline
\end{tabular}

$\begin{array}{llc}\text { Atrial fibrillation } & 1.14(0.97 \text { to } 1.35) & 0.11 \\ \text { Recent MI within } 30 & 1.39(1.20 \text { to } 1.61) & <0.001\end{array}$

days

\begin{tabular}{|c|c|c|}
\hline Remote MI & 1.24 (1.07 to 1.44$)$ & 0.006 \\
\hline Previous PCl & 1.03 (0.88 to 1.21$)$ & 0.70 \\
\hline \multicolumn{3}{|c|}{ Left ventricular ejection fraction } \\
\hline$\geq 50$ & Reference & Reference \\
\hline $35-49$ & $1.23(1.07$ to 1.42$)$ & 0.004 \\
\hline 20-35 & 1.72 (1.46 to 2.04$)$ & $<0.001$ \\
\hline$<20$ & 2.52 (1.91 to 3.32$)$ & $<0.001$ \\
\hline Heart failure & 1.90 (1.67 to 2.17$)$ & $<0.001$ \\
\hline $\begin{array}{l}\text { Peripheral arterial } \\
\text { disease }\end{array}$ & 1.45 (1.26 to 1.67$)$ & $<0.001$ \\
\hline $\begin{array}{l}\text { Cerebrovascular } \\
\text { disease }\end{array}$ & 1.37 (1.19 to 1.59$)$ & $<0.001$ \\
\hline Dementia & 2.46 (1.37 to 4.41$)$ & 0.003 \\
\hline
\end{tabular}

Continued
Table 4 Continued

\begin{tabular}{|c|c|c|}
\hline Variable & Adjusted OR (95\% Cl) & $P$ value \\
\hline Depression & 0.97 (0.66 to 1.42$)$ & 0.86 \\
\hline Psychosis & 1.42 (0.56 to 3.60$)$ & 0.46 \\
\hline \multicolumn{3}{|l|}{ Smoking status } \\
\hline Never & Reference & Reference \\
\hline Current & 1.01 (0.84 to 1.20$)$ & 0.96 \\
\hline Former & 1.01 (0.89 to 1.15$)$ & 0.87 \\
\hline $\begin{array}{l}\text { Chronic obstructive } \\
\text { pulmonary disease }\end{array}$ & 1.33 (1.18 to 1.49$)$ & $<0.001$ \\
\hline $\begin{array}{l}\text { Pulmonary circulatory } \\
\text { disorder }\end{array}$ & 1.68 (1.33 to 2.13$)$ & $<0.001$ \\
\hline
\end{tabular}

Serum creatinine ( $\mu \mathrm{mol} / \mathrm{L})$

\begin{tabular}{|lll}
\hline$<120$ & Reference & Reference \\
\hline $120-179$ & $1.67(1.44$ to 1.94$)$ & $<0.001$ \\
\hline$>=180$ & $2.78(2.23$ to 3.45$)$ & $<0.001$ \\
\hline Dialysis & $1.14(0.86$ to 1.50$)$ & 0.37 \\
\hline Diabetes & $0.96(0.85$ to 1.08$)$ & 0.49 \\
\hline Hypothyroidism & $0.75(0.52$ to 1.08$)$ & 0.12 \\
\hline Morbid obesity & $0.97(0.86$ to 1.09$)$ & 0.61 \\
\hline Primary cancer & $0.97(0.77$ to 1.22$)$ & 0.81 \\
\hline Metastatic cancer & $1.16(0.59$ to 2.31$)$ & 0.66 \\
\hline Anaemia & $1.25(1.08$ to 1.45$)$ & 0.002 \\
\hline Venous & $1.39(0.80$ to 2.44$)$ & 0.25 \\
thromboembolism & & \\
\hline Liver disease & $1.45(0.94$ to 2.25$)$ & 0.09 \\
\hline Alcohol abuse & $1.21(0.80$ to 1.81$)$ & 0.37 \\
\hline Frailty & $0.82(0.71$ to 0.95$)$ & 0.01 \\
\hline Redo sternotomy & $1.10(0.87$ to 1.40$)$ & 0.44 \\
\hline Emergent surgery & $2.91(2.49$ to 3.39$)$ & $<0.001$ \\
\hline Complex surgery & $1.32(1.14$ to 1.53$)$ & 0.0002 \\
\hline Surgery duration, per & $1.07(1.07$ to 1.08$)$ & $<0.001$ \\
\hline 10min & & \\
\hline
\end{tabular}

Total case volumes reflect the number of cases performed since 1991 until the date of the index procedure.

$\mathrm{MI}$, myocardial infarction; $\mathrm{PCl}$, percutaneous coronary intervention.

be explained by greater adherence to practice guidelines by female surgeons and anaesthesiologists, as well as their propensity for more effective interprofessional teamwork, and more active engagement in patient-centred care. ${ }^{345}$

The performance of female physicians has also been framed in terms of the challenges they must often overcome to practice effectively in the surgical specialties. For example, Wallis and colleagues suggested that it is possible that "these barriers might create a higher standard for women to gain entrance into the surgical workforce than men, resulting in the selection of a cohort of women that are proportionately more skilled, motivated, and harder working. ${ }^{12}$ This may be particularly true of cardiac surgery given it is among the most demanding 
specialties and is traditionally viewed as a male dominated field. Still, studies regarding medical emergencies outside of the COR setting have found that male healthcare professionals outperform their female colleagues, although at least in part because women's leadership is more likely to be challenged. ${ }^{61}$ Consequently, more research is needed to determine when and how to best support male and female physicians to promote effective practice and equity in the COR. As more women continue to pursue cardiac surgery and anaesthesiology, it will be important for research to deep-dive into their performance and experiences; this includes the impact of diversity on COR teamwork.

\section{Limitations}

First, an important limitation of our study is that we were only able to examine the impact of sex as gender variables were not available in the databases used. In the future, organisations may wish to consider incorporating measures of gender as routinely collected elements. Second, our findings are quantitative, and are limited by the inherent biases of observational studies. Prospective, qualitative research is warranted to further explore the role of physician sex and gender in the COR along with other potentially important factors such as ethnicity, language, geographical location, country of medical education and so forth. ${ }^{36} 37$ Third, an a priori power analysis was not performed. Fourth, our analyses were limited to physician characteristics as the characteristics of other COR providers were not available to us. Future research should consider the interaction of the surgeon and anaesthesiologist pair along with nurses, perfusionists, anaesthesia and surgical assistances and trainees.

\section{CONCLUSIONS}

Patient mortality and length of stay after cardiac surgery may vary by sex concordance of the attending surgeon-anaesthesiologist team. Further research is needed to examine the underlying mechanisms of these observed relationships.

\section{Author affiliations}

${ }^{1}$ Division of Cardiac Anesthesiology, University of Ottawa Heart Institute, Ottawa, Ontario, Canada

${ }^{2}$ Cardiovascular Research Program, Institute for Clinical Evaluative Sciences, Toronto, Ontario, Canada

${ }^{3}$ School of Epidemiology and Public Health, University of Ottawa, Ottawa, Ontario, Canada

${ }^{4}$ Department of Anesthesiology and Pain Medicine, University of Ottawa Faculty of Medicine, Ottawa, Ontario, Canada

${ }^{5}$ Clinical Epidemiology Program, Ottawa Hospital Research Institute, Ottawa,

Ontario, Canada

${ }^{6}$ Department of Innovation in Medical Education, University of Ottawa, Ottawa, Ontario, Canada

${ }^{7}$ Division of Cardiac Surgery, University of Ottawa Heart Institute, Ottawa, Ontario, Canada

${ }^{8}$ Peter Munk Cardiac Centre, University Health Network, Toronto, Ontario, Canada

Twitter Louise Y. Sun @sunlouise1
Acknowledgements The authors also acknowledge the usage of data compiled and provided by the Canadian Institute for Health Information. These data sets were linked using unique encoded identifiers and analysed at ICES. This study was supported by ICES, which is funded by an annual grant from the Ontario Ministry of Health (MOH) and the Ministry of Long-Term Care (MLTC) (Grant \# N/A). Parts of this material are based on data and information compiled and provided by the Canadian Institute for Health Information (CIHI) (Grant \# N/A). The authors acknowledge that the clinical registry data used in this analysis is from participating hospitals through CorHealth Ontario, which serves as an advisory body to the $\mathrm{MOH}$, is funded by the $\mathrm{MOH}$ and is dedicated to improving the quality, efficiency, access and equity in the delivery of the continuum of adult cardiac and stroke care in Ontario, Canada. In this project, frailty was identified using the Johns Hopkins ACG System V.10.

Contributors The corresponding author attests that all listed authors meet authorship criteria and that no others meeting the criteria have been omitted. LS: contributed to conception. LS and ABE: contributed to the design and analysis. LS, $\mathrm{SB}, \mathrm{VC}, \mathrm{DL}, \mathrm{TM}, \mathrm{ABE}$ and CE: Contributed to interpretation of data. LS and CE drafted the article. LS, SB, VC, DL, TM, ABE and CE: revised article critically for important intellectual content, gave final approval of the version to be published, agreed to act as guarantor of the work (ensuring that questions related to any part of the work are appropriately investigated and resolved).

Disclaimer The analyses, conclusions, opinions and statements expressed herein are solely those of the authors and do not reflect those of the funding or data sources; no endorsement is intended or should be inferred.

Competing interests None declared.

Patient consent for publication Not required.

Ethics approval The use of data in this project was authorised under section 45 of Ontario's Personal Health Information Protection Act, which does not require review by a Research Ethics Board.

Provenance and peer review Not commissioned; externally peer reviewed.

Data availability statement The dataset from this study is held securely in coded form at ICES. While legal data sharing agreements between ICES and data providers (e.g., healthcare organizations and government) prohibit ICES from making the dataset publicly available, access may be granted to those who meet pre-specified criteria for confidential access, available at www.ices.on.ca/DAS (email: das@ices. on.ca). The full dataset creation plan and underlying analytic code are available from the authors upon request, understanding that the computer programs may rely upon coding templates or macros that are unique to ICES and are therefore either inaccessible or may require modification.

Supplemental material This content has been supplied by the author(s). It has not been vetted by BMJ Publishing Group Limited (BMJ) and may not have been peer-reviewed. Any opinions or recommendations discussed are solely those of the author(s) and are not endorsed by BMJ. BMJ disclaims all liability and responsibility arising from any reliance placed on the content. Where the content includes any translated material, BMJ does not warrant the accuracy and reliability of the translations (including but not limited to local regulations, clinical guidelines, terminology, drug names and drug dosages), and is not responsible for any error and/or omissions arising from translation and adaptation or otherwise.

Open access This is an open access article distributed in accordance with the Creative Commons Attribution Non Commercial (CC BY-NC 4.0) license, which permits others to distribute, remix, adapt, build upon this work non-commercially, and license their derivative works on different terms, provided the original work is properly cited, appropriate credit is given, any changes made indicated, and the use is non-commercial. See: http://creativecommons.org/licenses/by-nc/4.0/.

ORCID iDs

Louise Y. Sun http://orcid.org/0000-0003-3381-3115

Cole Etherington http://orcid.org/0000-0002-7933-4593

\section{REFERENCES}

1 Cooper JB. Critical role of the surgeon-anesthesiologist relationship for patient safety. Anesthesiology 2018;129:402-5.

2 Attri JP, Sandhu GK, Mohan B, et al. Conflicts in operating room: focus on causes and resolution. Saudi J Anaesth 2015;9:457-63.

3 Katz D, Blasius K, Isaak R, et al. Exposure to incivility hinders clinical performance in a simulated operative crisis. BMJ Qual Saf 2019;28:750-7. 
4 Baker GR, Norton PG, Flintoft V, et al. The Canadian adverse events study: the incidence of adverse events among hospital patients in Canada. CMAJ 2004;170:1678-86. doi:10.1503/cmaj.1040498

5 Schraagen JM, Schouten T, Smit M, et al. Assessing and improving teamwork in cardiac surgery. Qual Saf Health Care ; 2010;19:e29.

6 Amacher SA, Schumacher C, Legeret C, et al. Influence of gender on the performance of cardiopulmonary rescue teams. Crit Care Med 2017;45:1184-91. doi:10.1097/CCM.0000000000002375

7 Mueller AS, Jenkins TM, Osborne M, et al. Gender differences in attending physicians' feedback to residents: a qualitative analysis. $J$ Grad Med Educ 2017;9:577-85. doi:10.4300/JGME-D-17-00126.1

8 Dayal A, O'Connor DM, Qadri U, et al. Comparison of male vs female resident milestone evaluations by faculty during emergency medicine residency training. JAMA Intern Med 2017;177:651-7.

9 Sarsons H, Akhtari M, Barron K. Interpreting signals in the labor market: evidence from medical referrals, 2017. Available: https:// scholar.harvard.edu/files/sarsons/files/sarsons_jmp.pdf [Accessed 11 Dec 2017].

10 Gambashidze N, Hammer A, Wagner A, et al. Influence of gender, profession, and managerial function on clinicians' perceptions of patient safety culture: a cross-national cross-sectional study. $J$ Patient Saf 2021;17:e280-7.

11 Burns KEA, Fox-Robichaud A, Lorens E, et al. Gender differences in career satisfaction, moral distress, and incivility: a national, crosssectional survey of Canadian critical care physicians. Can J Anaesth 2019;66:503-11.

12 Wallis CJ, Ravi B, Coburn N, et al. Comparison of postoperative outcomes among patients treated by male and female surgeons: a population based matched cohort study. BMJ 2017;359:j4366. doi:10.1136/bmj.j4366

13 Sharoky CE, Sellers MM, Keele LJ, et al. Does surgeon sex matter?: practice patterns and outcomes of female and male surgeons. Ann Surg 2018;267:1069-76. doi:10.1097/SLA.0000000000002460

14 Johnson TJ, Hickey RW, Switzer GE, et al. The impact of cognitive stressors in the emergency department on physician implicit racial bias. Acad Emerg Med 2016;23:297-305.

15 Canadian Medical Association. Cardiovascular / Thoracic Surgery Profile [Internet]. Ottawa, ON, 2018. https://cma.ca/sites/default/files/ 2019-01/cardiothoracic-surgery-e.pdf

16 Victor JC, Monto AS, Surdina TY, et al. Hepatitis a vaccine versus immune globulin for postexposure prophylaxis. N Engl J Med 2007;357:1685-94

17 Von Elm E, Altman DG, Egger M. The strengthening the reporting of observational studies in epidemiology (STROBE) statement: guidelines for reporting observational studies, 2018. http://www. jclinepi.com/article/S0895-4356(07)00436-2/pdf

$18 \mathrm{Tu}$ JV, Ko DT, Guo H, et al. Determinants of variations in coronary revascularization practices. CMAJ 2012;184:179-86.

19 Tu K, Campbell NR, Chen Z-L, et al. Accuracy of administrative databases in identifying patients with hypertension. Open Med 2007;1:e18-26.

20 et alJuurlink D, Preyra C, Croxford R. Canadian Institute for health information discharge Abstract database: a validation study, 2006. Available: http://www.ices.on.ca/Publications/Atlases-and-Reports/ 2006/Canadian-Institute-for-Health-Information
21 Hux JE, Ivis F, Flintoft V, et al. Diabetes in Ontario: determination of prevalence and incidence using a validated administrative data algorithm. Diabetes Care 2002;25:512-6.

22 Gershon AS, Wang C, Guan J, et al. Identifying patients with physician-diagnosed asthma in health administrative databases. Can Respir J 2009;16:183-8.

23 Schultz SE, Rothwell DM, Chen Z, et al. Identifying cases of congestive heart failure from administrative data: a validation study using primary care patient records. Chronic Dis Inj Can 2013;33:160-6.

24 Branch HA, Ministry O, Care L. Health analyst' S toolkit. Heal 2012:1-110.

25 Plessis du V, Beshiri R, Bollman R. Definitions of 'Rural'. Agric. Rural Work. Pap. Ser 2002

26 Sun LY, Tu JV, Bader Eddeen A, et al. Prevalence and long-term survival after coronary artery bypass grafting in women and men with heart failure and preserved versus reduced ejection fraction. J Am Heart Assoc 2018;7:1-14.

27 Development and evaluation of the Johns Hopkins University risk adjustment models for Medicare+Choice plan payment | Johns Hopkins ACG尺 system. Available: https://www.hopkinsacg.org/ document/development-and-evaluation-of-the-johns-hopkinsuniversity-risk-adjustment-models-for-medicarechoice-planpayment/

28 Sternberg SA, Bentur N, Abrams C, et al. Identifying frail older people using predictive modeling. Am J Manag Care 2012;18:e392-7.

29 Tran DTT, Tu JV, Dupuis J-Y, et al. Association of frailty and long-term survival in patients undergoing coronary artery bypass grafting. $J \mathrm{Am}$ Heart Assoc 2018;7. doi:10.1161/JAHA.118.009882. [Epub ahead of print: 2007 2018].

30 Corsini EM, Luc JGY, Mitchell KG, et al. Predictors of the response of operating room personnel to surgeon behaviors. Surg Today 2019;49:927-35

31 Pattni N, Bould MD, Hayter MA, et al. Gender, power and leadership: the effect of a superior's gender on respiratory therapists' ability to challenge leadership during a life-threatening emergency. $\mathrm{Br} \mathrm{J}$ Anaesth 2017;119:697-702.

32 Jones LK, Jennings BM, Higgins MK, et al. Ethological observations of social behavior in the operating room. Proc Natl Acad Sci U S A 2018;115:7575-80. doi:10.1073/pnas.1716883115

33 Tsugawa $Y$, Jena AB, Figueroa JF, et al. Comparison of hospital mortality and readmission rates for Medicare patients treated by male vs female physicians. JAMA Intern Med 2017;177:206-13. doi:10.1001/jamainternmed.2016.7875

34 Thomas WEG. Teaching and assessing surgical competence. Ann $R$ Coll Surg Engl 2006;88:429-32.

35 Birkmeyer NJO, Finks JF, Greenberg CK, et al. Safety culture and complications after bariatric surgery. Ann Surg 2013;257:260-5.

36 McCall L. The complexity of intersectionality. Signs 2005;30:1771-800

37 Crenshaw K. Mapping the margins: intersectionality, identity politics, and violence against women of color. Stanford Law Rev 1991;43:1241-99. 